We are grateful to Dr. Godfrey, for his letter has given us the opportunity to emphasize a very important point in the treatment of fibrosing alveolitis. A child with fibrosing alveolitis who initially responds to corticosteroids may deteriorate when the dose is reduced or stopped. As will be seen in Table 8 of our paper, 4 patients, following such a deterioration, improved on one occasion when corticosteroid treatment was restarted or increased. 3 of these subsequently deteriorated when the steroid dose was again reduced or stopped, did not then respond to a further 'adequate' steroid therapy and died. 2 other patients (Cases 7 and 9) responded to multiple courses of steroids after episodes of deterioration and have survived. It is not possible to predict which patients will continue to be steroid-responsive and it was this fact which led us to stress that steroid therapy for fibrosing alveolitis in children should comprise at least a year's treatment and that withdrawal should be cautious and protracted.

D. HULL and C. J. HEWITT University Hospital and Medical School, Clifton Boulevard, Nottingham NG7 $2 U H$.

\section{Pericardial effusion complicating umbilical venous catheterization}

Sir,

Recently we encountered an unusual complication of umbilical venous catheterization. A $3.4 \mathrm{~kg}$ female infant of an insulin-dependent diabetic mother received $4 \mathrm{ml}$ of $50 \%$ dextrose by push because of hypoglycaemia (blood glucose of $18 \mathrm{mg} / 100 \mathrm{ml} ; 1.0 \mathrm{mmol} / \mathrm{l}$ ), via an umbilical venous catheter. The infant then received 15\% dextrose by continuous infusion. $X$-ray of the chest and abdomen obtained subsequently showed the catheter coiled up in the heart with the tip in the right atrium. The catheter was pulled back into the inferior vena cava. At 52 hours of age the infant suddenly became dusky, had grunting respirations, and later became apnoeic and bradycardic. She was resuscitated and placed on intermittent positive pressure ventilation. Blood glucose was $103 \mathrm{mg} / 100 \mathrm{ml}(5 \cdot 7 \mathrm{mmol} / \mathrm{l})$. Chest $x$-ray showed cardiomegaly. The infant continued to do poorly and died after 15 minutes.

At necropsy the pericardial sac was found to be distended with $28 \mathrm{ml}$ clear yellow fluid. There was a small haematoma measuring $0.2 \times 0.2 \times 0.1 \mathrm{~cm}$ in the anterior wall of the left atrium and adjacent to this haematoma there was a perforation measuring $0.1 \mathrm{~cm}$ in diameter. Biochemical analysis of the pericardial fluid showed glucose $3020 \mathrm{mg} / 100 \mathrm{ml}(168 \mathrm{mmol} / \mathrm{l})$, total protein $11.7 \mathrm{~g} / \mathrm{l}$, calcium $5.0 \mathrm{mg} / 100 \mathrm{ml}(1.25 \mathrm{mmol} / \mathrm{l})$, and sodium $92 \mathrm{mEq} / \mathrm{l}(92 \mathrm{mmol} / \mathrm{l})$.

The inordinate amount of glucose in the pericardial fluid and the rent in the left atrium indicate that the fluid reached the pericardial space during the manual infusion of $50 \%$ dextrose. It is reasonable to assume that the catheter tip originally was in the left atrium and that it recoiled into the right atrium after the rapid push of the dextrose. Though simple puncture of the atrial wall by the catheter tip could have been the basis of the observed complication, the cutting force of the jet stream produced by rapid infusion seemed an alternative possibility. We have found in vitro that when $50 \%$ dextrose is injected rapidly through a 5 French umbilical catheter, pressures as high as $550 \mathrm{mmHg}$ may be produced.

\section{DILIP M. PUROHIT and ABNER H. LEVKOFF} Department of Pediatrics, Medical University of South Carolina, 80 Barre Street, Charleston, S. C. 29401, USA.

\section{Rapid assessment of gestational age at birth}

Sir,

We have assessed the gestational age of 408 newborn babies using the method of Parkin et al. (Archives, 1976, $51,259)$ which is based on four external characteristics. The mean of differences between gestational age, according to the last period, and that assessed by the total score was $+1 \cdot 26$ days and the standard deviation \pm 8.01 days. Thus, the $95 \%$ confidence limits of \pm 16 days in our series are very similar to those obtained by the above authors. The relation of total score to gestational age is shown in the Fig. The means of the gestational ages are plotted against total score. $95 \%$ confidence limits for prediction of gestational age from the score are also shown by the horizontal lines. The curve has been drawn by free hand. We find the method simple, quick, and quite accurate, so that it can be used in every day clinical practice.

ALEX. PEONIDES

Children's Asylum Maternity Hospital, Thessaloniki, Greece.

B. KATSOUGIANNOPOULOS Department of Hygiene, University of Thessaloniki, Greece.

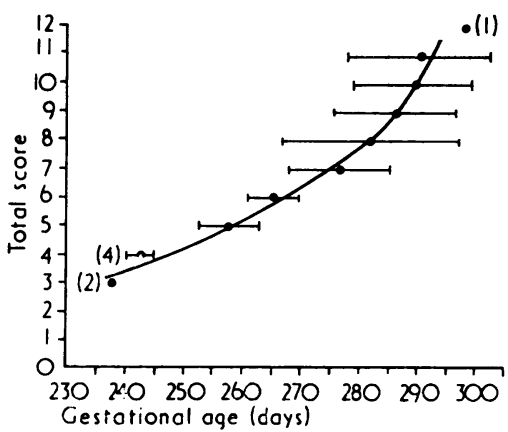

Fig. Relation of total score to gestational age. 